International Journal of Current Microbiology and Applied Sciences

ISSN: 2319-7706 Volume 6 Number 8 (2017) pp. 2659-2666

Journal homepage: http://www.ijcmas.com

Original Research Article

https://doi.org/10.20546/ijcmas.2017.608.317

\title{
Assay of Anti-Oxidative Activity of Seed Extracts Derived from Rice (Oryza sativa L) Varieties
}

\author{
Anita Kumari*, Geetanjali Kannojiya, Anil Kumar and Anil Kumar Gaur \\ Molecular Biology and Genetic Engineering Collage of Basic Sciences and Humanities, \\ G.B. Pant University of Agriculture and Technology, Pantnagar, India \\ *Corresponding author
}

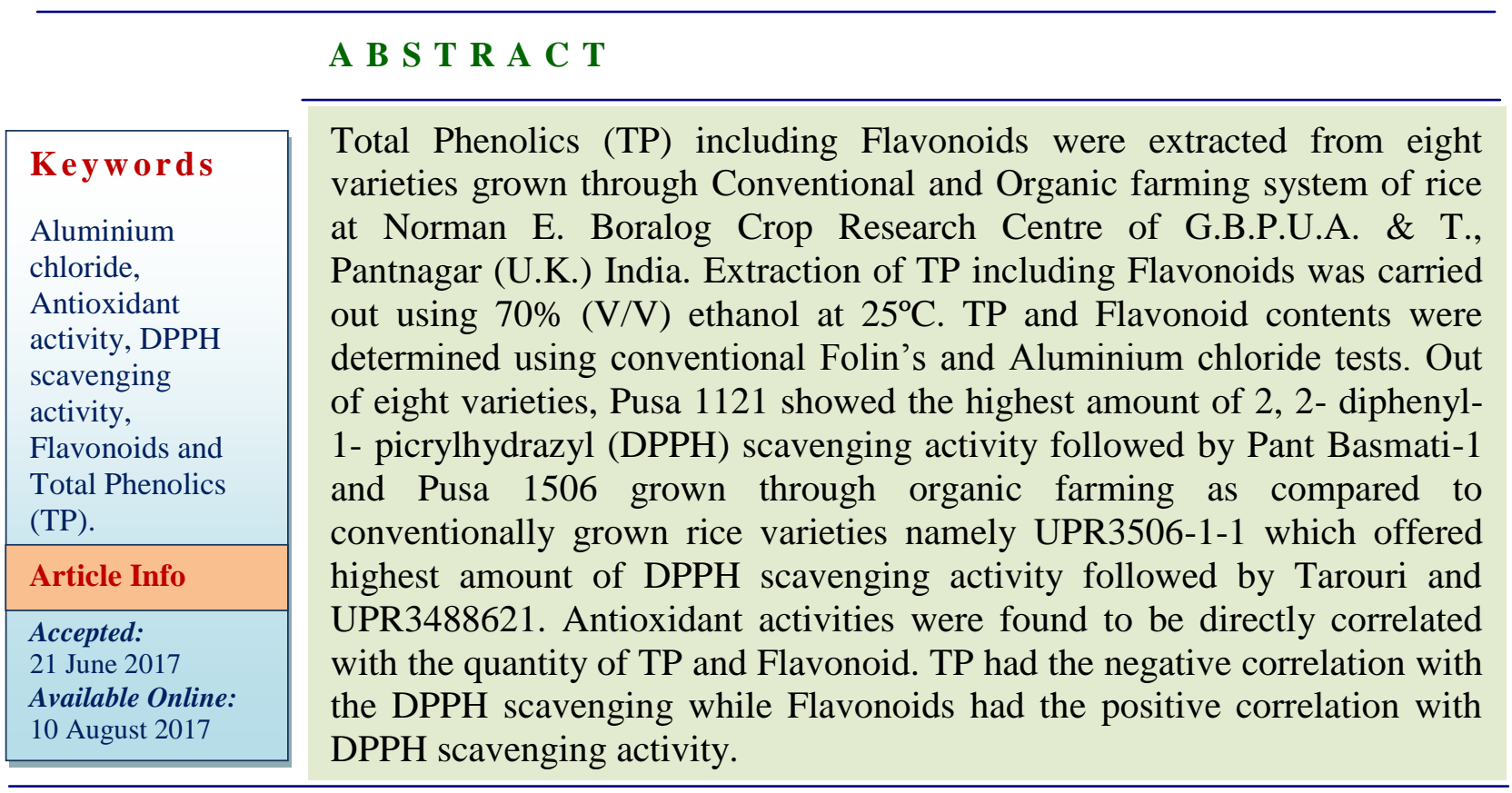

\section{Introduction}

Organic farming is gaining momentum during recent decades due to increased public awareness towards environment and food safety concerns. Organic farming is a promising opportunity for farmers who shall like to promote biodiversity, geochemical cycles for enhancement of biological activity in the soil which in turn facilitate least use of off-farm inputs and on management practices. This will ensure restoration, sustainability and improvise ecological harmony (Sirikul, et al., 2009). The organic farming is characterized by the prohibition of a majority of synthetic chemicals in both crop and livestock production. Conventional farming is also referred to as a regular farming system which is widely applied to any nonorganic farming system and relies on external inputs to achieve high production yields (Hole et al., 2005).

The organic farming seeks to promote the development of a food production system that is required for social, ecological, economical and sustainable environment. The principle of organic food production is being encouraged 
and enhanced to maintain increased long-term fertility of soils, to avoid the use of synthetic fertilizers and pesticides as well to maintain genetic diversity of the production system. It is also a requirement to consider the wider social and ecological impact of the food production and processing system in order to produce food of high quality in adequate quantity (Bourn and Prescott, 2002).

Recently the popularity of organic rice has increased in many regions around the world even though the organic rice market remains relatively immature. The decreased cost of production per acre and environmentallyfriendly production methods have become appealing to some producers. However, the effect of farming practice on production yields, chemical compositions, bioactive components compared to conventional production have been still a question for most producers. Rice (Oryza sativa L) is the most important cereal crop in the world, consumed as a whole kernel which commonly produced by milling and leaving a rice bran as a byproduct. India has sufficient area under rice cultivation, as it is one of the principal food crops.

India is one of the leading producers of this crop. Rice is the basic food crop and being a tropical plant, it flourishes comfortably in hot and humid climate. Rice is the staple food of eastern and southern parts of India. Rice is rich in many nutrient components including carbohydrates, proteins, certain fatty acids and micronutrients.

It is also a good source of many bioactive non-nutrient compounds, known as antioxidants, including phenolic compounds (Zhonghua, et al., 2013). Thus we attempted to look the production of secondary metabolites in two different farming practices organic and conventional for antioxidant activities found in seeds of rice in order to correlate the antioxidant activities which are found richly in fruits and vegetables while grains are considered as major sources of energy, protein, vitamins, dietary fiber and minerals (Slavin, et al., 1999; Bimova and Pokulda, 2009). Antioxidant activity reduces the risk of heart disease, cancer and other chronic diseases (Pezzuto and Park, 2002).

The molecules with antioxidant activity contained in rice include phenolics pertaining to flavonoids, anthocyanins, proanthocyanidins, tocopherols, tocotrienols, c-oryzanol, and phytic acid (Piebiep \& Henrique, 2014). However, japonica rice varieties were found to be richer in antioxidant compounds compared with indica rice varieties.

The antioxidant constituents of plant materials are important for human health and protection from various ailments including coronary heart disease and cancer (Loliger, 1991).

\section{Materials and Methods}

\section{Material collection}

Sixteen rice varieties of organic and conventional farming were collected from Norman E. Boralog Crop Research Centre of G.B.P.U.A. \& T., Pantnagar (Uttrakhand), India are described as below in table 1 .

\section{Chemicals and reagents}

Gallic acid, ascorbic acid, Folin-Ciocalteu reagent, $\mathrm{Na}_{2}$ EDTA, 2, 2- diphenyl-1picrylhydrazyl (DPPH), potassium ferricyanide, ferric chloride, and trichloroacetic acid (TCA) were purchased from Sigma (Sigma-Aldrich $\mathrm{GmbH}$, Sternheim, Germany) and HiMedia (HiMedia Laboratories, L.B.S. Marg, Mumbai). All other reagents and solvents used were of analytical grade. 


\section{Preparation of extract}

Rice seeds $(10 \mathrm{gm})$ from each variety were soaked in the solvent $(70 \% \mathrm{~V} / \mathrm{V}$ ethanol in water) and it was kept in the ultrasonic water bath for $40 \mathrm{~min}$ at $25^{\circ} \mathrm{C}$. After this period, extracts were centrifuged at 5000rpm for 15 min. Aqueous layer was separated and dried under vacuum rotary evaporator. These extracts were stored at $-20^{\circ} \mathrm{C}$.

\section{Determination of total phenolics content}

The total phenolic content of extracts was determined using the Folin-Ciocalteau phenol reagent. A $0.02 \mathrm{~mL}$ of each sample (concentration $0.2 \mathrm{mg} / \mathrm{mL}$ ) was added to 0.98 $\mathrm{mL}$ of freshly diluted 10-fold FolinCiocalteau phenol reagent (Sisco Research Laboratories Pvt. Ltd, India). After $10 \mathrm{~min}$, $0.8 \mathrm{~mL}$ of $7.5 \% \mathrm{Na}_{2} \mathrm{CO}_{3}$ was added to the mixture. The reaction was allowed to complete for $1 \mathrm{~h}$ in the dark at room temperature then measured at $765 \mathrm{~nm}$ on a spectrophotometer $\quad\left(G e n e s y s^{\mathrm{TM}} 10 \mathrm{UV}\right)$. Gallic acid was used as a standard and results were calculated as Gallic acid equivalents (GAE $\mathrm{mg} / \mathrm{g}$ ) of the sample. The reactions were performed in triplicate and the mean value was obtained.

\section{Determination of flavonoid content}

Flavonoid content was determined using the aluminium chloride colorimetric method. Extracts of conventional and organic farming rice were dissolved in distilled water $(1 \mathrm{mg} / \mathrm{mL})$ in the test tubes followed by addition of $5 \% \mathrm{NaNO}_{2}$. After 5 min, $10 \%$ $\mathrm{AlCl}_{3}(0.3 \mathrm{~mL})$ was added in these tubes. After $6 \mathrm{~min}, 1 \mathrm{M} \mathrm{NaOH}(2 \mathrm{~mL})$ was added in these tubes. The absorbance was measured at $510 \mathrm{~nm}$ using a Spectrophotometer $\left(\right.$ Genesys $\left.^{\mathrm{TM}} 10 \mathrm{UV}\right)$. The results were expressed as mg Catechin equivalents (CE)/g samples.

\section{Determination of scavenging activity of DPPH radical}

The antioxidant activity (AOA) was correlated by the measurement of 2, 2diphenyl-1-picrylhydrazyl (DPPH) radical scavenging activity. A $0.2 \mathrm{~mL}$ of the extraction solution $(1 \mathrm{mg} / \mathrm{mL}$ in distilled water) in test tube was mixed with $3.8 \mathrm{~mL}$ of 95\% (V/V) ethanol and $1 \mathrm{~mL}$ of DPPH solution (1 $\mathrm{mM}$ in $95 \%$ ethanol). The samples were kept in a dark place at $25^{\circ} \mathrm{C}$ and after 30 min absorbance was measured using a spectrophotometer (Genesys $\left.{ }^{\mathrm{TM}} 10 \mathrm{UV}\right)$. All the measurements were carried out in triplicate. The scavenging ratio was calculated using the formula:

$\%$ inhibition $=\left[\left(1-\mathrm{A}_{517 \mathrm{~nm}}\right.\right.$, sample $/ \mathrm{A}_{517 \mathrm{~nm}}$, control) $] \times 100$

\section{Statistical analysis}

All measurements were recorded in triplicates and these were expressed as mean \pm SE. The significance of mean differences between chemical compositions and bioactive compounds within different rice varieties were statistically compared using analysis of variance (ANOVA) at the $5 \%$ probability level $(\mathrm{p} \leq 0.05)$.

\section{Results and Discussion}

\section{Total phenolics and flavonoid content}

Total phenolics content was estimated by Gallic acid as depicted in figure 1 and expressed as milligrams of gallic acid equivalent (GAE). Higher phenolics and flavonoid content were found in the ethanol extracts as compared with methanol extracts as per report of Goffman and Bergman, 2004; Stratil, et al., 2007. Similarly, another study of organic rice cultivated in Thailand reported significant higher phenolics content compared 
with conventionally cultivated rice which were reported as 1.88 and $1.39 \mathrm{mg} / \mathrm{g}$ GAE, respectively, along with same trend of antioxidant activities reported by Sirikul, et al., 2009 in organic and conventionally cultivated rice. Extracts were found to contain considerable amount of phenolics content from $0.0763 \pm 0.003$ to $0.4536 \pm 0.0218 \mathrm{mg}$ $\mathrm{GAE} / \mathrm{g}$.

The rice variety UPR-3506-1-1 exhibited the highest total phenolics contents in organic farming of rice upon analysis among the extracts followed by Pant Dhan-18, Tarouri, Pusa-1506, UPR-3488621, Pant Bas-1, Pusa1121 and Pusa Bas-1. While in the case of conventional farming of rice extracts from UPR-3506-1-1 showed the highest phenolics content followed by Pusa-1121, UPR3488621, Pant Bas-1, Pusa-1506, Pant Dhan18 and Tarouri. Phenolics content is among one of very important derivative of plant system as these confer scavenging ability (Hatano, et al., 1989). Phenolics present in plants have received considerable attention because of their potential antioxidant activities (Pan, et al., 2008). Plant materials rich in phenolics are widely used in the food industry because they retard oxidative damage of lipids by improving nutritional value and quality of food products derived from these plants (Kahkonen, et al., 1999). Thus their analysis is imperative.

The flavonoids content in different rice varieties was also investigated using the aluminium chloride colorimetric method. Organic farming rice varieties showed the high amount of flavonoids than the conventional farming rice varieties upon comparison amongst the different varieties rice extracts. The rice variety Tarouri offered the highest amount of flavonoids (2.52 \pm $0.093 \mathrm{CE} \mathrm{mg} / \mathrm{g}$ ) followed by Pusa 1509 (1.41 $\pm 0.09 \mathrm{CE} \mathrm{mg} / \mathrm{g})$ and UPR 3488621(0.93 \pm $0.202 \mathrm{CE} \mathrm{mg} / \mathrm{g})$. But in the case of conventional farming rice extracts from the rice variety UPR3488621 showed highest compared to other rice varieties as shown in figure 2.

The scavenging effect of rice extracts was evaluated using the DPPH method. Absorbance at $517 \mathrm{~nm}$ of DPPH radical in this method was recorded. The color changes from purple to yellow which lead decrease in its absorbance at wavelength $517 \mathrm{~nm}$ (Naik, et $a l$. , 2003). The DPPH radical scavenging capacity varied from 23.46 to $50.7 \%$ in organic farming rice compared to conventional farming rice which showed variation from 7.43 to $47.8 \%$. It was observed that for organic farming rice extracts, Pusa 1121 showed the greatest scavenging activity with the value of $50.7 \pm 0.65 \mathrm{mg} / \mathrm{g}$, followed by Pant Bas-1, Pusa 1509, UPR3488621, Pusa Bas-1, Tarouri, Pant Dhan-18 and UPR3506-1-1 while in the conventional Farming rice extracts the rice variety UPR3506-1-1 showed the highest scavenging activity with the value of $47.8 \pm 1.53 \mathrm{mg} / \mathrm{g}$, followed by Tarouri, Pant Dhan-18, UPR3488621, Pusa1121, Pusa 1509, Pant Bas-1and Pusa Bas-1 as shown in figure 3.

Higher percentage of DPPH scavenging is correlated with higher antioxidant capacity (Sultana, et al., 2009). Antioxidant activity of extracts is strongly dependent on the solvent due to the different antioxidant potentials of compounds with different polarity (Caunii, et al., 2012; khatoon, et al., 2013).

Furthermore, the correlation coefficient $\left(\mathrm{R}^{2}\right)$ between total phenolics including flavonoids and antioxidant activities in each variety of rice extract was determined. Total phenolics content showed negative correlation with DPPH scavenging while flavonoids showed the positive correlation with DPPH scavenging (Table 2). 
Fig.1 The total phenolics content of conventional farming and organic farming rice varieties. Values expressed are mean \pm standard deviation $(n=3)$. The total phenolics contents are expressed as mg of Gallic Acid Equivalent (GAE)/gm of extract

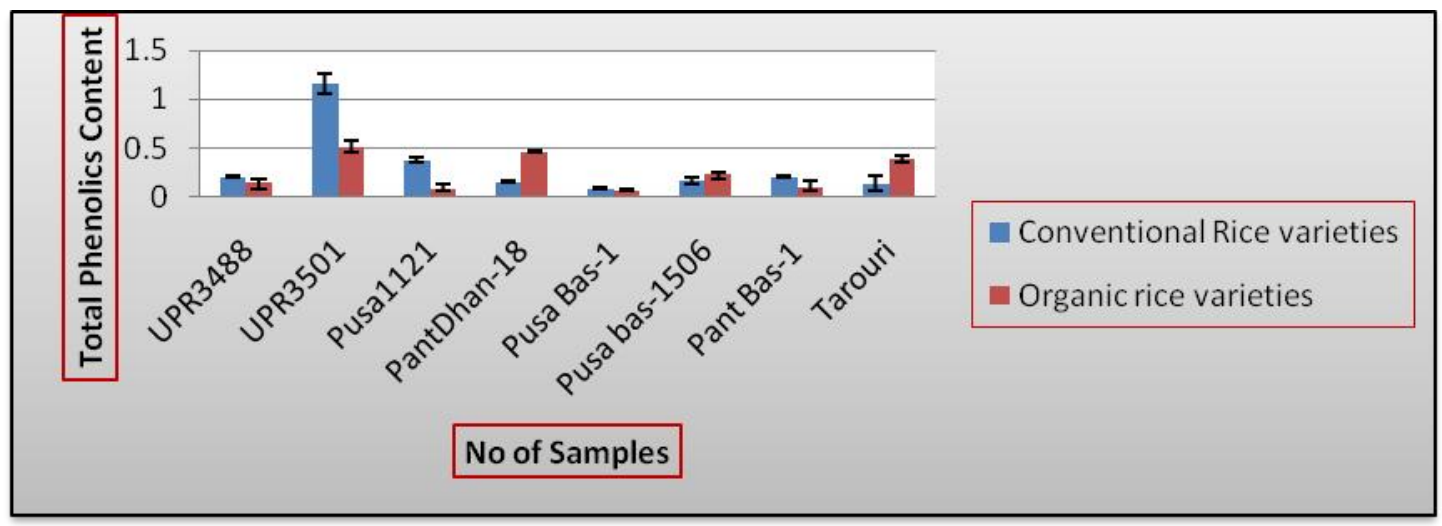

Fig.2 Flavonoids content of conventional farming and organic farming rice varieties. Values expressed are mean \pm standard deviation $(n=3)$. The flavonoids content are expressed as $m g$ of Catechin Equivalent (CE)/gm of extract

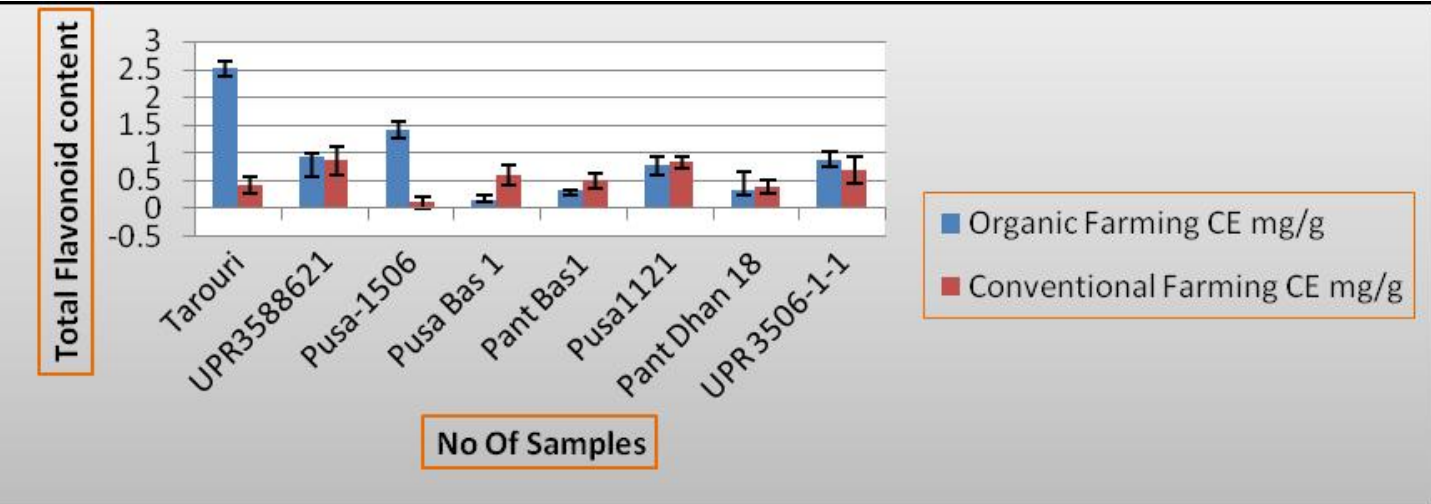

Fig.3 The scavenging activity of conventional farming and organic farming rice varieties on DPPH radical. Values expressed are mean \pm standard deviation $(n=3)$

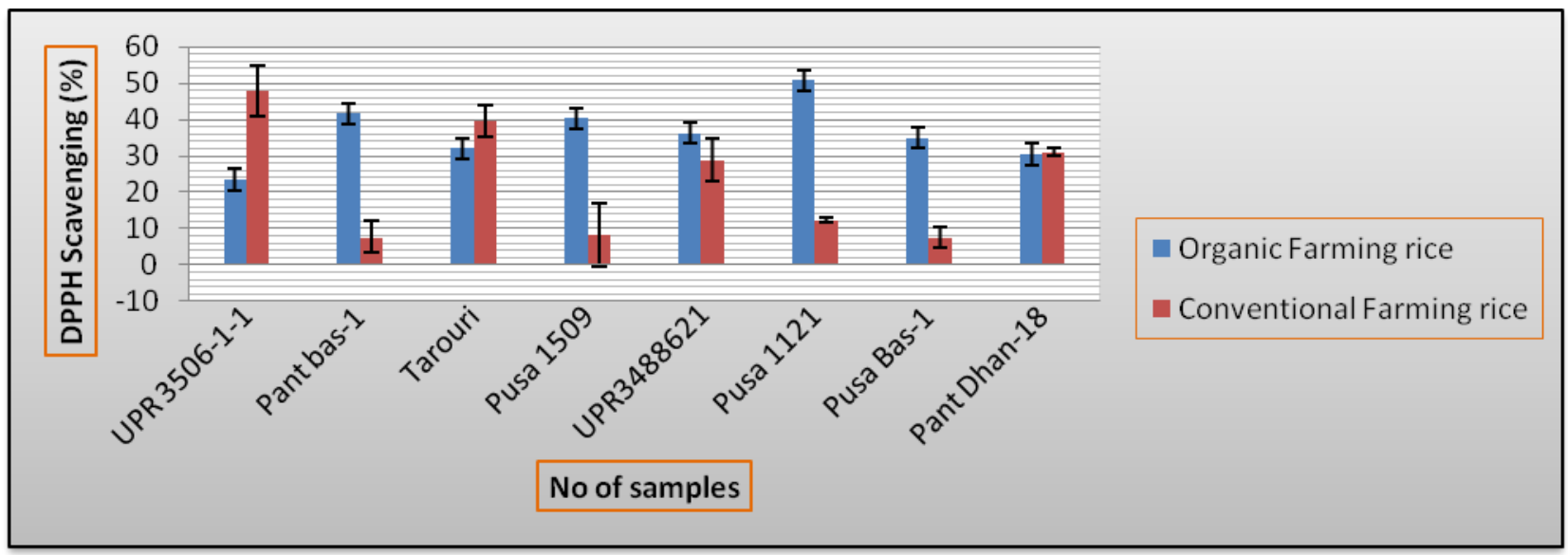


Table.1 Description of the rice varieties used in the study

\begin{tabular}{|l|l|}
\hline Organic Farming rice varieties & Conventional Farming rice varieties \\
\hline Tarouri & Tarouri \\
\hline UPR3588621 & UPR3588621 \\
\hline Type-3 & Type-3 \\
\hline Pusa Bas 1 & Pusa Bas 1 \\
\hline Pant Bas1 & Pant Bas1 \\
\hline Pusa1121 & Pusa1121 \\
\hline Pant Dhan 18 & Pant Dhan 18 \\
\hline UPR 3506-1-1 & UPR 3506-1-1 \\
\hline
\end{tabular}

Table.2 Variations in phenolics, flavonoids contents and antioxidant capacity among rice varieties

\begin{tabular}{|l|l|l|l|l|l|l|}
\hline \multirow{2}{*}{ S. No. } & \multicolumn{2}{|c|}{ DPP } & \multicolumn{2}{c|}{ TFC } & \multicolumn{2}{c|}{ TPC } \\
\cline { 2 - 7 } & Organic & conventional & Organic & \multicolumn{1}{c|}{ conventional } & Organic & conventional \\
\hline UPR 3506-1-1 & $23.46 \pm 7.08$ & $47.8 \pm 1.53$ & $0.85 \pm 0.061$ & $0.69 \pm 0.139$ & $0.504 \pm 0.0785$ & $1.159 \pm 0.108$ \\
\hline Pant bas-1 & $41.56 \pm 4.41$ & $7.58 \pm 2.97$ & $0.32 \pm 0.052$ & $0.5 \pm 0.075$ & $0.1014 \pm 0.059$ & $0.204 \pm 0.009$ \\
\hline Tarouri & $32.04 \pm 4.27$ & $39.46 \pm 4.15$ & $2.52 \pm 0.093$ & $0.41 \pm 0.088$ & $0.387 \pm 0.034$ & $0.139 \pm 0.074$ \\
\hline Pusa 1509 & $40.24 \pm 8.54$ & $8.17 \pm 9.02$ & $1.41 \pm 0.09$ & $0.1 \pm 0.062$ & $0.2362 \pm 0.012$ & $0.162 \pm 0.028$ \\
\hline UPR3488621 & $36.27 \pm 5.92$ & $28.79 \pm 1.8$ & $0.93 \pm 0.202$ & $0.85 \pm 0.150$ & $0.1517 \pm 0.036$ & $0.206 \pm 0.009$ \\
\hline Pusa 1121 & $50.7 \pm 0.65$ & $12.21 \pm 4.56$ & $0.76 \pm 0.08$ & $0.83 \pm 0.066$ & $0.089 \pm 0.047$ & $0.375 \pm 0.021$ \\
\hline Pusa Bas-1 & $34.96 \pm 2.94$ & $7.43 \pm 7.94$ & $0.14 \pm 0.013$ & $0.6 \pm 0.108$ & $0.0763 \pm 0.003$ & $0.093 \pm 0.01$ \\
\hline Pant Dhan-18 & $30.42 \pm 1.09$ & $30.9 \pm 0.7$ & $0.31 \pm 0.042$ & $0.38 \pm 0.072$ & $0.4536 \pm 0.0218$ & $0.153 \pm 0.01$ \\
\hline
\end{tabular}

Value represent in the results are mean \pm SE of three replicates.

In conclusion, conventional and organic farming of rice varieties was compared in this study for natural products found in ethanol extracts for extracting majority of phenolics including flavonoid compounds. The variety of rice that showed the highest phenolic compounds after extraction was UPR3506-11 for both conventional and organic farming rice varieties.

Highest flavonoids content after extraction were shown in rice variety Tarouri in the case of organic farming and rice variety UPR3488621 in case of conventional farming. Organic and conventional farming rice varieties Pusa 1121 and UPR3506-1-1 showed highest amount of \%DPPH scavenging activity followed by rice varieties Pant Basmati-1 and Tarouri.

The findings of this study suggest that nutritional values of these rice varieties since their ethanolic extracts found to contain bioactive compounds which ensures potential of selected varieties for protection against human health hazards. Therefore, identified rice varieties should be developed for food applications as healthy products by food industries using such varieties to add value to food products derived from rice. Thus, information obtained from this study shall be helpful for the production of value-added rice rich in natural antioxidants.

\section{Acknowledgements}

We wish to acknowledge Dr D. K. Singh, Professor, Department of agronomy, Collage of Agriculture, G.B. Pant University of Agriculture and Technology, Pantnagar, India for providing us the matured rice seed material obtained through organic and conventional farming from summer grown varieties in the year 2015. We are also thankful to the Department of Biotechnology, Government of India, for funding this work under the Program Mode Support in Agricultural Biotechnology Initiative. 


\section{References}

Bimova, P. and Pokulda, R. 2009. Impact of organic fertilizers on total antioxidant capacity in head cabbage. Hort. Sci. (Prague). 36: 21-25.

Bourn, D. and Prescott, J. 2002. A comparison of the nutritional value, sensory Qualities, and Food Safety of Organically and Conventionally Produced Foods. Critical Reviews in Food Science and Nutrition. 42(I): 1-34.

Cao, L. Y., Zhan, X. D., Chen, S. G., Feng, Y., Wu, W. M., Shen, X. H., and Cheng, S. H. 2010. Breeding Methodology and Practice of Super Rice in China. Rice Science. 17: 87-93.

Caunii, A., Pribac, G., Grozea, I., Gaitin, D. and Samfi, I. 2012. Design of optimal solvent for extraction of bio-active ingredients from six varieties of Medicago sativa. Chem Cent J. 6:123131.

Dutta, A. K., Gope,P.S., Banik,S., Makhnoon,S., Siddiquee, M.A. and Kabir, Y., 2012. Antioxidant properties of ten high yielding rice varieties of Bangladesh. Asian Pacific Journal of Tropical Biomedicine. S99-S103.

Goffman, F. and Bergman, C. J. 2004. Rice kernel phenolic content and its relationship with antiradical efficiency. J. Sci. Food Agric. 84: 1235-1240.

Hatano, T., Edamatsu, R., Mori, A., Fujita, Y., Yasukara, T., Yoshida, T. 1989. Effects of the interaction of tannins with co-existing substances. VI. Effects of tannins and related polyphenols on superoxide anion radical and on 2, 20diphenylpicrylhydrazyl. Chem Pharm Bull. 37: 2016-2021.

Hole, D. G., Perkins, A. J., Wilson, J. D., Alexander, I. H., Grice, F. and Evans A. D. 2005. Does organic farming benefit biodiversity? Biological Conservation. 122: 113-130.
Kahkonen, M. P., Hopia, A. I., Vuorela, H.J., Rauha, J. P., Pihlaja, K., Kujala, T. S., Heinonen, M. 1999. Antioxidant activity of plant extracts containing phenolic compounds. J Agri Food Chem. 47:3954-3962.

Khatoon, M., Islam, E., Islam, R., Rahman, A. A., Khurshid Alam, A. H. M., Khondkar, P., Rashid, M. and Parvin, S. 2013. Estimation of total phenol and in vitro antioxidant activity of Albizia procera leaves. BMC Research Notes. 6:121.

Lai, P., Li, K. Y., Lu, S. and Chen, H. H. 2009. Phytochemicals and antioxidant properties of solvent extracts from Japonica rice bran. Food Chem. 117: 538-544.

Liu, Z., Saenkod, C., Huang, J. and Gong, Y. 2013. Anti-oxidative biochemical properties of extracts from some Chinese and Thai rice varieties. African journal of Food Science. 7(9): 300-305.

Naik, G. H., Priyadarsini, K. I., Satav, J. G., Banavalikar, M. M., Sohoni, D. P., Biyani, M. K. and Mohan, H. 2003. Comparative antioxidant activity of individual herbal components used in Ayurvedic medicine. Phytochemistry. 63: 97104.

Pan, Y. K., Wang, S., Huang, H., Wang, X., Mu, C., He X, Ji. J. and Huang, F. 2008. Antioxidant activity of microwaveassisted extract of longan (Dimocarpus longan Lour.) peel. Food Chem. 106:1264-1270.

Pezzuto, J. M. and Park, E. J. 2002. Auto oxidation and antioxidants. In Encyclopedia of Pharmaceuticals Technology (J. Swarbrick and J.C. Boylan, eds.) pp. 97-113, Marcel Dekker, New York, NY.

Sirikul, A., Moongngarm, A. and Khaengkhan, P., 2009. Comparison of proximate composition, bioactive compounds and antioxidant activity of 
rice bran and defatted rice bran from organic rice and conventional rice. As. J. Food Ag-Ind. 2: 731-743.

Slavin, J. L., Martini, M. C., Jacobs, D. R. and Marquart, L., 1999. Plausible mechanisms for the protectiveness of whole grains. Am. J. Clin. Nutr. 70: 459-463.

Stratil, P., Klejdus, B. and Kuban, V. 2007. Determination of phenolic compounds and their antioxidant activity in fruits and cereals. Talanta 71: 1741-1751.
Sultana, B., Anwar, F. and Ashraf, M. 2009. Effect of Extraction Solvent Technique on the Antioxidant Activity of Selected Medicinal Plant Extracts. Molecules. 14:2167-2180.

USDA, National Organic Standards Board (NOSB). 2007. Organic production and organic food: Information access tools, United States Department of Agriculture (USDA), http://www.nal.usda.gov.

\section{How to cite this article:}

Anita Kumari, Geetanjali Kannojiya, Anil Kumar and Anil Kumar Gaur. 2017. Assay of AntiOxidative Activity of Seed Extracts Derived from Rice (Oryza sativa L) Varieties. Int.J.Curr.Microbiol.App.Sci. 6(8): 2659-2666. doi: https://doi.org/10.20546/ijcmas.2017.608.317 